\title{
PERI PHYSEOS PSYCHES: SOBRE A NATUREZA DA ALMA NO FEDRO DE PLATÃO ${ }^{1}$
}

\author{
Maria Aparecida de Paiva Montenegro* \\ mariamonte_7@hotmail.com
}

\begin{abstract}
A Natureza ama ocultar-se.
Não encontrarias os limites da alma, mesmo todo o caminho percorrendo, tão profundo logos possui.
\end{abstract}

Heráclito $^{2}$

\begin{abstract}
RESUMO No passo 245 c do Fedro de Platão, no contexto do segundo discurso de Sócrates (no qual ele compõe sua palinodia dirigida a Eros), o filósofo chama atenção para a importância de "se tornar explícita a natureza da alma, dos seus estados e atos, assim como indagar se esta natureza é humana ou divina". Pretendo mostrar que Platão, nesse diálogo, tenta fundamentar a natureza mista da alma: em parte racional em parte passional. Essa ambiguidade constitutiva mostra-se diretamente correlacionada àquelas referentes às formas de Amor, Loucura e Retórica abordadas ao longo do diálogo, à medida que estas podem ser tanto perniciosas quanto prodigiosas, a depender do modo como se as conduz. Nessa perspectiva, meu propósito é defender a presença, na filosofia pensada por Platão, de elementos passionais imprescindíveis ao sucesso de sua atividade, cabendo ao filósofo alcançar, por meio de uma formação apropriada, a maestria para reverter aquilo que pode mergulhá-lo na ignorância e, consequentemente, na escravidão e na

1 Trabalho realizado com apoio da CAPES - PROCAD e do CNPq - Universal.

* Professora do Departamento de Filosofia da Universidade Federal do Ceará (UFC). Recebido em 26/05/2010 e aprovado em 02/07/2010.

2 Heráclito. Fragmentos Contextualizados. Tradução, apresentação e comentários de Alexandre Costa. Rio de Janeiro, Difel, 2002, fragmentos CXXIII e XLV.
\end{abstract}

KRITERION, Belo Horizonte, nº 122, Dez./2010, p. 441-457. 
infelicidade, naquilo que justamente irá conduzi-lo na direção oposta: a do amor à Sabedoria.

Palavras-chave Platão, Fedro, physis, psyche.

ABSTRACT In Plato's Phaedrus 245-c, when Socrates delivers his second speech (in which he composes his palinodia addressed to Eros), the philosopher calls attention to the importance of "first understanding the truth about the nature of the soul, divine or human, by examining what it does and what is done to it". I intend to point out that in this dialogue, Plato tries to found the mixed composition of the soul: partly rational, partly passionate. This constitutive ambiguity seems to be directly related to those different kinds of Love, Madness and Rhetoric examined in the dialogue, inasmuch as they could be either beneficial or harmful, depending on the way they are managed. Therefore, my purpose is to point that regarding philosophy as conceived by Plato, the appealing of passionate elements are quite indispensable for its successful activity, so that the philosopher must receive an adequate upbringing in order to reach the mastery of turning elements that could draw him into deep ignorance, consequently into slavery and unhappiness, in their very opposite, which is the love of Wisdom.

Keywords Plato, Phaedrus, physis, psyche.

Admitir que Platão seja um filósofo da natureza parece à primeira vista absurdo, sobretudo quando se tem em mente importantes passagens de sua obra, tal como Fédon (96-a, 98-b) ${ }^{3}$ e Leis (889-b e segs.), ${ }^{4}$ nas quais se encontram críticas explícitas ao projeto daqueles - posteriormente chamados de physiologoi ${ }^{5}$ - para quem a physis remeteria às causas primeiras de cada coisa, reputadas a elementos puramente materiais.

"Sócrates: (...) Na minha juventude, me senti extraordinariamente atraído para esse ramo do saber chamado ciência da natureza (physeos historian) (...) Pois bem, meu amigo, essa maravilhosa esperança, tive de passar sem ela! À medida que avançava na leitura, descobria um homem (Anaxágoras) que não fazia o mínimo caso do espírito (nous), que nenhuma responsabilidade lhe atribuía na ordenação das coisas, remetendo-a sim para o ar, o éter, a água e tantas outras causas destituídas de propósito(...) “ "Eles (os "filósofos da natureza") propõem que o fogo, a água, terra e ar devem sua existência ao crescimento espontâneo e de modo algum à arte e que por meio dessas substâncias inteiramente inanimadas é que os corpos físicos secundários - a terra, sol, lua e estrelas - foram produzidos. (...)

5 Aristóteles, Metafísica, $\Delta, 1005$ a -b. 
Contudo, cumpre notar que a crítica platônica parece recair mais sobre a concepção de natureza defendida por essa tradição e não propriamente sobre a ideia de que o conhecimento consiste em fornecer explicações acerca da natureza das coisas. ${ }^{6}$ Mais precisamente, é como se Platão identificasse um grande equívoco no projeto daqueles primeiros filósofos, quando atribuíram à physis - processo de desenvolvimento que engendra as coisas - uma causalidade espontânea e sem reflexão (aitias automates), relacionada, como já dissemos, a elementos puramente materiais. Da fala do Ateniense em Leis X (892-a e segs.), depreende-se o esforço do filósofo em corrigir esse equívoco, à medida que leva o referido personagem a afirmar a anterioridade da alma em relação à matéria (somaton), devendo, portanto, constituir a causa desta última:

Quanto à alma, meu caro, quase todo mundo parece ignorar sua verdadeira natureza e potência, ignorando não só outros fatos a respeito dela, mas especialmente sua origem - que ela é uma das primeiras formas de existência, nascida antes de todas as formas corpóreas e, mais que qualquer outra coisa, é ela quem governa todas as alterações e transformações do que é corpóreo. E se este realmente for o caso, não se segue que todas as coisas relativas à alma são necessariamente anteriores em sua origem com relação ao que pertence ao corpo, admitindo-se que a alma precede o corpo $^{7}$

Nesse caso, se 'natureza' é o termo comumente empregado para designar o processo pelo qual as substâncias primárias foram geradas, uma vez desfeito o equívoco, é a alma (psyche) e não a matéria (somatos) que deverá receber a apropriada atribuição de natureza. Ademais, em diálogos como Sofista (265-c e segs.), ${ }^{8}$ Platão parece identificar, ainda como consequência do

6 Cf. Hadot, P. O vôo de Ísis: Ensaio sobre a história da idéia de natureza. Tradução de Mariana Sérvulo. São Paulo, Loyola, 2004, 359 pgs.

7 Psychen, o hetaire, egnoekenai kindyneuousi men oligou sympantes hoion te on tynchanei kai dynamin hen echei, ton te allon autes peri kai de kai geneseos, hos em protois esti, somaton emprosthen panton genomene, kai metaboles te auton kai metakosmeseos hapases archei pantos mallon: ei de estin tauta houtos har' ouk ex anankes ta psyches syngene protera an eie gegonota ton somati [892B] prosekonton, ouses g'autes presbyteras e somatos; (Platão. Leis, X, 892a. Texto grego retirado de Perseus Digital Library (http://www. perseus.tufts.edu/hopper). As regards the soul, my comrade, nearly all men appear to be ignorant of its real nature and its potency, and ignorant not only of other facts about it, but of its origin especially,- - how that it is one of the first existences, and prior to all bodies, and that it more than anything else is what governs all the changes and modifications of bodies. And if this is really the state of the case, must not things which are akin to soul be necessarily prior in origin to things which belong to body, seeing that soul [892b] is older than body? (Plato, Laws X, 892 a. Tradução de Benjamin Jowett. New York, Prometheus Books, 2000.

8 "Estrangeiro: Considera os animais e tudo que é mortal, inclusive as plantas e tudo sobre aTerra (...) e todos os corpos inanimados (...) Diremos que foi somente através da obra de um deus que, não tendo sido antes, vieram a ser? Ou aceitaremos a crença expressa e divulgada de que...

Teeteto: Que crença?

Estrangeiro: A de que a natureza os gera a partir de alguma causa espontânea destituída de inteligência criadora. Ou diremos que são criados pela razão e pelo conhecimento divino oriundo de um deus? (...) 
mesmo equívoco, a cisão operada entre physis e techne, tal que aquela teria passado a implicar processos supostamente naturais, destituídos de uma ação do pensamento, enquanto esta resultaria de um programa elaborado por uma inteligência (nous). Corrigido o equívoco, essa cisão deixaria de existir, de maneira que a techne passaria a constar como a atividade própria à verdadeira natureza - a alma -, fazendo-se necessário apenas diferenciar seus modos de manifestação: divina e humana.

Toda essa tentativa de reconstrução do modo como em Platão se relacionam as concepções de alma e de natureza pareceu-nos necessária para compreendermos melhor o que encontramos no segundo discurso de Sócrates ${ }^{9}$ proferido no Fedro (245-c), quando o personagem alega a necessidade de "se conhecer a verdade acerca da natureza da alma divina e humana, considerando seus estados e suas ações". Se a alma deve ser ela mesma pensada como a verdadeira natureza de tudo que existe (e não a matéria), em que consistiria a natureza da própria alma? Em outras palavras, qual seria a natureza da natureza?

Ora, é preciso estar atento para as diferentes acepções com que o termo physis é empregado nessa primeira parte do segundo discurso de Sócrates, em que predomina uma argumentação próxima ao tipo lógico-dedutivo. Assim, o termo é associado à noção de arche, cuja tradução mais usual é a de 'origem'. Contudo, se o traduzirmos por 'princípio' (CHANTRAINE, 1980), veremos que se torna possível abarcar, além da acepção de 'origem', as acepções de 'pressuposto' e de 'fonte'. À luz de tal polissemia, podemos dizer que Sócrates parte do princípio (pressuposto) de que a alma é imortal, dada a sua capacidade de mover-se a si mesma, para chegar à conclusão de que a alma é o próprio princípio (origem) do movimento; isto porque, enquanto tal, não pode ser movida por outro princípio (fonte), senão por si mesma. Enquanto princípio (em todas as acepções referidas), nem pode ser gerada, nem pode perecer, donde se reitera o argumento inicial de que ela é imortal. Nessa perspectiva, a natureza da alma, aqui identificada à essência da mesma (ouses physeus psyches), quer seja divina ou humana, é a imortalidade e o princípio do movimento.

Terei como suposto que as coisas que as pessoas classificam como naturais são produzidas pela arte divina e que as coisas compostas pelo ser humano a partir daquelas são produtos da arte humana".

9 Vale salientar que o segundo discurso de Sócrates é proferido na condição de palinodia, isto é, de reparação às ofensas dirigidas contra Eros em seu primeiro discurso (237b - 241d), a exemplo do discurso de Lísias apresentado por Fedro (231a- 234e). Examinaremos esse aspecto mais adiante. 
Porém, quando se trata de descrever a natureza da alma no que diz respeito à sua constituição mesma (tes ideas), ${ }^{10}$ Sócrates recorre a um outro expediente argumentativo; ou seja, lança mão de um mito - no caso, o mito da parelha alada -, alegando que caracterizá-la (a alma) daria ensejo a uma exposição longa e minuciosa, cabível apenas a um deus - consequentemente, inacessível ao gênero humano.

A esse respeito, cumpre notar que o recurso ao mito, imagem ou alegoria, antecedido por uma espécie de justificativa acerca da dificuldade ou inacessibilidade do discurso humano a uma explicação precisa de algo em sua essência, ou ainda, da própria origem ou causa das essências, ocorre também em outros diálogos, não necessariamente como um privilégio de Sócrates. Em República 506-e, ${ }^{11}$ Sócrates confessa-se incapaz de expressar o que vem a ser o próprio Bem - causa da ciência e da verdade - propondo enunciar tão somente o que seria o filho do Bem, o qual seria muito semelhante àquele:

Por Zeus, ó Sócrates, respondeu Glauco, não te afastes como se tivesses chegado ao fim. É que para nós bastará que, como discorreste a respeito da justiça, da temperança e das demais virtudes, assim também discorras sobre o bem.

Também para mim, ó companheiro, disse eu, certamente bastará. Mas temo que não seja capaz, e que na minha sofreguidão me exponha ao ridículo de modo inconveniente. Mas ó, felizes homens, no momento deixemos de lado o que venha a ser o bem em si mesmo; é que ele me parece muito elevado para que o presente impulso atinja o que pelo menos no momento eu penso que ele seja. Mas quero falar sobre aquele que parece ser filho do bem e muito semelhante a ele, se também vos agradar, mas, se não, deixemos passar.

Está bem, disse ele, fala; de outra vez pagarás a exposição sobre o pai.

É então que se segue a analogia do Sol e da Linha Dividida ${ }^{12}$ que, por sua vez, antecedem a célebre imagem (eidos) da caverna. ${ }^{13}$ No Timeu 29 b-c, é o personagem homônimo que apresenta uma justificativa para o caráter aproximativo e não exato de seu discurso acerca da origem do universo:

“(...) explicações que dizem respeito ao que é estável, fixo e discernível ao entendimento, são elas mesmas estáveis e inabaláveis (...) Por outro lado, explicações que damos daquilo que foi formado como imagem por semelhança do real, posto que são explicações do que é uma semelhança, são dotadas de probabilidade (...)

10 Para um exame mais detido a respeito da tradução da expressão grega tes ideas por 'constituição', vide a introdução à tradução francesa do diálogo de Letitia Mouze em Platon. Phédre. Paris, Librairie Genérale Française, Edition Les Classiques de Philosophie, Livre de Poche, 2007, p.79.

11 Platão. A República. Tradução, introdução e notas de Eleazar Magalhães Teixeira. Fortaleza, Edições UFC, 2009.

12 Cf. República VI, 508-b a 511-e.

13 Op. Cit. 514-a a 517-e. 
Consequentemente, Sócrates, não fiques surpreso se na nossa abordagem de um grande número de matérias envolvendo os deuses e o vir a ser do universo nos mostrarmos incapazes de apresentar explicações sempre e em todos os aspectos completamente coerentes e exatas; pelo contrário, ficaremos satisfeitos se formos capazes de oferecer explicações que não sejam inferiores à de outros quanto à probabilidade, lembrando que eu, que falo, e vós, que julgais (meu discurso) não passamos de criaturas humanas, cabendo-nos aceitar a narrativa provável dessas matérias e nos abstermos de investigar além dela". ${ }^{14}$

Já no Protágoras 320 b-c, ${ }^{15}$ é o habilidoso sofista que propõe narrar um mito, a fim de atender à provocação de Sócrates no sentido de mostrar que a virtude é passível de ser ensinada. O que se segue é uma versão platônica do mito de Prometeu que, nesse contexto, concede relevo justamente à condição humana, em tudo mais frágil em relação aos demais animais. Segundo o mito, tal fragilidade teria provocado tamanha reação em Prometeu, que este, num gesto ousado de transgressão às leis divinas, rouba de Hefesto e Atena a sabedoria técnica concernente ao fogo e com isto concede ao homem uma certa flâmula de racionalidade.

Ora, tudo se passa como se a precariedade intrínseca à condição humana aludida tanto no mito de Prometeu quanto no mito da parelha alada que examinaremos a seguir fosse exemplarmente ilustrada na limitação admitida pelos próprios personagens dos diálogos platônicos quanto à impossibilidade de proceder a uma narrativa precisa acerca da origem e da essência das coisas. Em outras palavras, o frequente uso do plano dramático ${ }^{16}$ dos diálogos para ilustrar o conteúdo filosófico que os mesmos engendram permite-nos entrever, nesse caso particular, uma certa tendência de Platão a admitir os limites do

14 Platão. Timeu, 29 b-c. Tradução, textos complementares e notas de Edson Bini. São Paulo, Edipro, 2010.

15 "Sócrates: - Eu, portanto, Protágoras, considerando tais fatos, julgo que a virtude pode ser ensinada. Quando, porém, te ouço afirmar isso, eu me dobro e fico pensando que tem sentido o que dizes por julgar que em muitas coisas és experiente (...) Se então nos podes mostrar claramente que a virtude é ensinável, não recuses, mostra.

Protágoras: - Ora, Sócrates, (...) não me recusarei; mas querem que eu mostre como um velho falando a jovens, sob a forma de um mito, ou devo expor num discurso?

Então, muitos dos que estavam ali sentados lhe responderam que poderia expor do modo que quisesse. Protágoras: - Realmente parece-me (...) mais bonito contar-lhes um mito" (Platão. Protágoras, 320-b c. Tradução e estudo introdutório de Eleazar Magalhães Teixeira. Fortaleza, Edições UFC, 1986).

16 Abordaremos esse aspecto mais adiante. Contudo, para um exame mais aprofundado acerca dessa relação entre o plano dramático e o plano conceitual nos diálogos platônicos, recomendamos, entre outros, a leitura de Blondell, R. The Play of character in Plato's dialogues. Cambridge, Cambridge University Press, 2004; Sallis, J. Being and Logos: Reading the Platonic Dialogues. Bloomington and Indianapolis, Indiana University Press, 1996; Sayre, K. Plato's Literary Garden: How to read a platonic dialogue. Notre Dame Indiana, University of Notre Dame Press, 1995, 292 pgs.; Kahn, C. H. Plato and the Socratic dialogue: the Philosophical use of a Literary form. New York, Cambridge University Press, 2004, 431pgs. 
logos humano como consequência da precariedade de sua (humana) natureza. ${ }^{17}$ Como corolário, admitiria a debilidade de suas possibilidades de conhecimento, de certo modo condenado à probabilidade. Por outro lado, contudo, parece ao mesmo tempo reabilitar o valor do mito e da menção às divindades como recurso apropriado à narrativa filosófica acerca da arche, algo aparentemente desprestigiado pelos physiologoi em prol de um discurso materialista, supostamente mais racional e, consequentemente, mais verdadeiro.

Voltando ao Fedro (245c e segs.), uma vez admitida a incapacidade de Sócrates quanto a proferir um discurso preciso acerca da natureza da alma, cumpre-lhe apenas dizer com o que a alma se assemelha com a vantagem de tal expediente ser mais breve. A alma é agora comparada a uma força natural composta de um carro puxado por uma parelha alada de dois cavalos e conduzida por um cocheiro. Como bem se conhece o mito, enquanto a alma divina conta com dois cavalos de boa raça, belos e obedientes à condução do auriga, a alma dos outros seres, entre os quais se encontra o ser humano, seria formada por apenas um cavalo de boa raça junto a um outro, mestiço e desobediente. Dessa diferença fundamental decorreria a dificuldade intrínseca de guiarmos o nosso próprio carro. Com efeito, as almas divinas ocupam-se de pôr em movimento ascendente aquilo que é pesado em direção à morada dos deuses, no topo do mundo, onde compartilham um banquete divino. Dali elas atingem a superfície externa do céu, de onde são conduzidas de volta por meio de um movimento circular que permite a contemplação das realidades eternas, exteriores ao céu. Já as almas humanas padecem da constante peleja contra a pusilanimidade do cavalo mestiço, em persistente movimento contrário ao do cavalo de boa raça, estabelecendo, com relação às almas semelhantes, um embate competitivo, no afã de alcançarem na frente a planície da verdade, onde está situado o pasto mais adequado para nutrir as asas. O resultado seria a impossibilidade de ver, senão de muito longe - e ainda de relance - aquelas realidades supracelestes, além de uma perda das próprias asas, uma vez que o descontrole na condução do carro alado acarreta um atropelamento recíproco

17 Algo, aliás, bastante compatível com a reiterada ignorância admitida pelo próprio personagem Sócrates ao longo de vários diálogos. Curiosamente, contudo, o reconhecimento desse limite humano quanto ao pleno conhecimento do que vem a ser a essência mesma das coisas parece situar Platão num plano epistemológico um tanto distinto daquele que a história da filosofia ter-lhe-ia consagrado, a saber, o de pai da metafísica (Cf. Reale, G. História da Filosofia Antiga. São Paulo, Loyola, 1995, 596pgs.). Mais precisamente, encontramos, nessas diferentes alusões aos limites humanos do conhecimento, um forte argumento para uma interpretação menos dogmática acerca do papel que as concepções metafísicas ocupam na filosofia platônica. Ou seja, à luz dessa perspectiva, a consagrada 'teoria platônica das formas' consistiria mais em um construto aproximativo, assumidamente metafórico, com o fito de estabelecer parâmetros minimamente estáveis para o conhecimento do mundo (em constante fluxo), do que propriamente uma doutrina que duplicaria o mundo num sentido literal. 
e a consequente mutilação das asas de muitas almas. Tal perda promove a precipitação abrupta dessas almas na direção da terra, de modo a tombar nos corpos sólidos e a ajustar-se aos mesmos, assumindo inicialmente formas humanas.

Ora, o mito reitera metaforicamente a noção já apresentada no Fédon (66b e segs.), segundo a qual a ligação com o corpo representaria o aprisionamento da alma, impossibilitando-a de alcançar o alvo de suas aspirações - a verdade. Todavia, cumpre lembrar que, ainda de acordo com o mito, as asas também têm uma natureza própria e esta consiste em conduzir um corpo pesado para cima, na direção da morada dos deuses. Nesse sentido, a alma passa a ser pensada como aquilo que, de entre tudo que participa do corpóreo, mais participa da natureza divina $(246 \mathrm{~d}-\mathrm{e})$. Por conseguinte, se de um lado a alma humana se reveste não somente de uma constituição compósita e heterogênea, mas, sobretudo, intrinsecamente precária, de outro lado ela tem a chance de se elevar (recuperar as asas) e angariar para si um certo parentesco com a divindade.

Por conseguinte, é justamente essa ambiguidade que caracteriza a natureza da alma humana e, consequentemente, de toda a sua existência. Paralelamente, o logos humano também seria dotado dessa mesma característica: de um lado, pode incorrer em graves equívocos e simplesmente inverter a ordem e o sentido das coisas - como seria o caso dos physiologoi a respeito das causas primeiras do cosmos; de sofistas como Trasímaco, por exemplo, para quem a justiça é a conveniência dos mais fortes (República, I, 338c e segs.); de retóricos como Lísias ${ }^{18}$ e do próprio Sócrates, em seu primeiro discurso, à medida que identificam o Eros à loucura e à doença. Por outro lado, o logos também pode ser submetido a uma 'reparação' e formular, tal como as que Platão propõe, apresentações sobre a natureza das coisas que, apesar de não serem exatas, gozem de uma probabilidade jamais inferior às explicações daqueles.

Há ainda um importante aspecto que, por assim dizer, singulariza a noção de alma encontrada no Fedro (FERRARI, 2002). Com efeito, enquanto no Fédon (78 c) ela é suposta como uma realidade homogênea, não dividida, imortal na medida mesma em que é incompósita, em nosso diálogo a alma

18 Alguns comentadores supõem que o personagem Lísias não passaria de um disfarce de Isócrates, contemporâneo e adversário de Platão, dado que igualmente se insurgia contra os sofistas, além de reivindicar para si o status de verdadeiro filósofo. Com efeito, pode-se constatar que Platão retira vários argumentos do Elogio de Helena de Isócrates para construir o primeiro discurso de Sócrates contra Eros. A esse respeito, Cf. Mazzara, G. 'Lysias et Isocrates: ironie et simulation dans le Phèdre'. in. Understanding the Phaedrus - Proceedings of the Symposium Platonicum, Perugia. Ed. by Livio Rossetti. International Plato studies, v. 1, Sankt Augustin, Academia Verlag 1992, 328 pgs. 
(humana e divina), além de tripartida, é, toda ela, imortal. Mesmo na República, a despeito da tripartição amplamente abordada no Livro IV (439d e segs.), tem-se, no Livro X (611b e segs.; 612a), como que um retorno à concepção de uma alma una, imortal. No Timeu (41b-d; 42d-e), apenas a parte racional da alma é considerada imortal (43a - 44c). Somente no Livro X das Leis (892a e segs.) é que se encontra uma visão mais próxima dessa contida no Fedro, uma vez que as moções atribuídas à alma imortal cobrem todo o espectro dos estados anímicos.

Em face de essa divergência concernente ao modo como o atributo da imortalidade é conferido à alma nos diferentes diálogos acima mencionados, seria o caso de se supor uma mudança ou evolução no pensamento de Platão quanto a esse tema tão importante para a sua filosofia? Não nos cabe aqui enveredar por esse caminho, dado que envolve a complexa questão das diferentes vertentes de leitura dos diálogos que, em última análise, buscam obter a posição do próprio filósofo acerca dos temas abordados apenas por seus personagens. Considerando a deliberada opção do filósofo de não expor seu próprio pensamento em primeira pessoa e a consequente inexistência de proposições de tipo assertórico em sua obra, aderimos à sugestão de Trabattoni (2003), segundo a qual para estudar Platão é preciso, antes de tudo, aceitar o risco da hipótese. Em seguida, buscar pelo seu pensamento no todo dos diálogos e não na fala de alguns personagens privilegiados. De resto, atentar para que as aparentes contradições quanto a concepções como a de alma e muitas outras sejam compreendidas não como sinal de uma evolução, mas a partir dos diferentes contextos em que são suscitadas. É, pois, ao contexto que devemos nos reportar para entender por que uma certa concepção é suposta de determinado modo e não exatamente do mesmo modo em que aparece em outro diálogo.

Assim, se no Fédon a imortalidade é atribuída a uma alma suposta como um todo incompósito e não partido é porque a ênfase parece recair sobre a difícil inversão da noção mais tradicional de que a morte é o pior acontecimento humano - o que vai requerer também o apelo do contexto dramático, no qual a serenidade com que Sócrates se prepara para morrer é, no mínimo, desconcertante. Ou seja, nesse caso, não é a ambiguidade da alma que está em destaque, mas a sua imortalidade. Já no Fedro, ambos os atributos da alma imortalidade e ambiguidade - ocupam o foco e se suas três partes são supostas como imortais, talvez haja um propósito preciso que se depreende tanto no plano da argumentação, quanto no plano dramático. Com efeito, supor que as três partes da alma (e não apenas a racional) são imortais parece indicar, exatamente num contexto em que Sócrates procede a uma palinodia ou discurso 
de reparação dirigido a Eros, que à alma humana é dada a possibilidade de, analogamente, também reparar a sua própria precariedade, a depender da vida que decidir levar. Vejamos essa hipótese um pouco mais detidamente.

Em primeiro lugar, cumpre reiterar o que para mim se tornou uma grande chave interpretativa dos diálogos de Platão, da qual Ferrari (2002) igualmente lança mão no exame específico do Fedro. Trata-se de um sofisticado interjogo entre o plano dramático e o plano propriamente argumentativo, ao qual o comentador denomina de interrelação entre foreground e background; ou ainda, entre aquilo que é dito e aquilo que é mostrado. Esta interação daria conta de atrelar definitivamente as duas partes constantes do diálogo, aparentemente dissociadas: a primeira, na qual se apresentam os três discursos acerca de Eros (o discurso de Lísias, proferido por Fedro, seguido pelos dois discursos de Sócrates), à parte que se segue e que parece operar uma ruptura temática, dado que os interlocutores passam um tanto abruptamente a discutir sobre a arte de escrever e recitar belamente um discurso - em uma palavra, a arte retórica.

De acordo com Ferrari (2002), haveria no Fedro uma espécie de revezamento entre aquilo que é mostrado - o pano de fundo - e aquilo que é dito, ou seja, aquilo que ocupa o centro da discussão travada em cada uma das partes do diálogo. Desse modo, a temática central (foreground) da primeira parte, a saber, a relação de equivalência entre Eros e Filosofia, apresenta-se através dos discursos proferidos como imprecações e elogios voltados a Eros em meio a um cenário campestre (229 a e segs.), apreciado e enaltecido até mesmo por Sócrates que sempre preferiu a cidade, por acreditar não ter nada a aprender no campo (230d). Segundo o comentador, tem-se aí, como pano de fundo (background), a arte retórica; eu diria, tem-se a retórica posta em ato, uma vez que assistimos à magistral desmontagem do discurso de Lísias, mestre dessa arte, em ambos os discursos de Sócrates. Por outro lado, quando é a retórica que passa a ocupar a temática central do diálogo (foreground), tem-se como pano de fundo (background) o modo propriamente filosófico de conduzir uma investigação; nesse caso, tem-se a própria filosofia posta em ato. Isto posto, vejamos agora em que medida essa chave de leitura auxilia-nos no que dizíamos acerca da natureza da alma no Fedro.

Num primeiro momento, podemos já argumentar que a caracterização da alma como uma parelha de cavalos alados guiada por um cocheiro constitui um recurso retórico bastante condizente com o cenário pastoral no qual se trava o diálogo. Segundo Farness (1991), a escolha por esse cenário guardaria uma certa ironia de Platão, uma vez que a verdade acerca da prática mais valorizada àquela época na cidade - a arte retórica - será restaurada somente longe de seus muros, no campo, lugar onde supostamente não seria encontrada. 
Ademais, o mito da parelha alada mostra a habilidade retórica de Platão ao valer-se de uma metáfora bastante concreta, encarnada, para falar sobre algo etéreo e abstrato como a alma. Contudo, é no fato de inserir essa descrição da natureza da alma no contexto de um discurso de reparação dirigido a Eros que podemos identificar a maestria retórica do filósofo.

Com efeito, Eros, atacado no discurso de Lísias e no primeiro discurso de Sócrates precisa ser reabilitado, uma vez que, no Banquete, mais precisamente no discurso de Diotima (203b e segs.), é identificado à própria figura do filósofo, dada a atividade que cumpre a ambos, qual seja, a busca pelo Belo. Ademais, não podemos esquecer que o Eros de Diotima é igualmente constituído de uma natureza ambígua, não podendo ser nem belo nem feio. Desse modo, é descrito como sendo filho da insólita união entre Poros (Recurso) e Penia (Penúria), de maneira a herdar a natureza de ambos. Assim, ao mesmo tempo em que viverá como a mãe, feio e maltrapilho, mendigando por migalhas, terá de seu pai os belos e abundantes engenhos, vindo a utilizá-los para atrair seu amado.

Analogamente, o filósofo não pode ser tomado por sábio, uma vez que este não pode almejar aquilo que já possui - a sabedoria. ${ }^{19}$ Tampouco poderia ser considerado um mero ignorante, dado que este não poderia amar aquilo cuja existência desconhece por inteiro. Portanto, seria um ser ambíguo: ao mesmo tempo em que carregaria a precariedade de não saber, bem como a fragilidade da ferramenta (o logos) de que dispõe para obter o que lhe falta, teria a nobreza de admitir que não sabe, além de ser capaz de produzir o mais engenhoso recurso (a dialética) para aproximar-se daquilo que ama e ao qual aspira.

Sua ambiguidade, contudo, não deve confundi-lo com logógrafos como Lísias, uma vez que este não estaria propriamente interessado na verdade, mas no efeito que seus discursos são capazes de produzir em seus ouvintes por meio de seu astucioso uso das palavras. Por último, porém provavelmente o mais importante, não poderia ser confundido com alguém como Isócrates que, apesar de ser apenas mencionado ao final do diálogo e de modo aparentemente dispensável (Fedro, 278e - 279a), talvez seja o verdadeiro adversário de Platão no que diz respeito ao que se deve entender por atividade filosófica. ${ }^{20} \mathrm{Com}$ efeito, em seu Discurso contra os Sofistas ${ }^{21}$ Isócrates denuncia as práticas

19 No Fedro 278d, Sócrates admite que tal designação só caberia aos deuses, não sendo digna de um homem.

20 Ver nota 18, acima.

21 Isocrates XIII. Against the sophists. Translated by Joshua Tinsdale. In: http://classicpersuasion.org/pw/ isocrates. 
extorsivas e enganadoras dos sofistas, vindo a pleitear para si o verdadeiro status de filósofo, associado a um papel formador de toda a juventude ateniense rumo ao domínio da retórica para o pleno exercício da vida política. Ademais, criticava Platão por sua prática elitista da dialética junto aos poucos frequentadores da Academia (TRABATTONI, 1996).

Por conseguinte, reparar-se frente a Eros no Fedro, valendo-se para tanto de uma abordagem mítico-filosófica daquela que, de acordo com a mitologia tradicional, corresponde ao par amoroso do deus - Psyche - implica, em última análise, em assegurar a possibilidade de uma filosofia inseparável da retórica. Isto porque se trata de uma atividade precária como é a alma humana, não podendo, por esse motivo, prescindir da persuasão. ${ }^{22}$ Todavia, deve-se distinguir de atividades como a de Lísias (Fedro, 271a - 272a-c) e, sobretudo, como a de Isócrates, uma vez que não se aplicaria a qualquer um, mas somente àqueles capazes de se dedicar ao estudo da natureza da própria natureza (a alma), por meio do qual podem inverter o sinal negativo de sua condição ambígua.

Por outras palavras, mostrar que a filosofia não pode prescindir da arte retórica, não se igualando, porém, à sofística (Fedro, 272 d-e; 273a e segs.), nem à retórica pan-helenística de Isócrates parece o mesmo que admitir que a precariedade da condição humana, a ambiguidade intrínseca a sua alma e ao logos que lhe é concedido não o impedem de buscar alguma forma de reparação. Tal reparação está relacionada à possibilidade de se aspirar a alguma forma de conhecimento verdadeiro, dentro dos limites possíveis ao humano o que, no final do diálogo, é identificado à dialética (277e). Esta arte, apesar de não constituir nenhum método que forneça propriamente uma teoria ou um corpo de definições, pressupõe, por sua vez, um profundo estudo acerca do destinatário para o qual se dirigirá; como já dissemos, pressupõe um profundo estudo da natureza da alma humana (Fedro, 277b-d). Assim, a dialética não só não pode, como também não pretende oferecer nenhuma doutrina acabada, pois para cada alma será necessária uma abordagem que lhe seja propícia.

Todavia, à medida que propõe submeter a exame determinada questão a partir de divisões em espécies e gêneros num contexto acessível à alma de seu interlocutor, o usuário da dialética pode e deve pleitear o trabalho de

22 Lembremo-nos do que diz Protágoras, no diálogo homônimo, antes de discorrer sobre a origem da condição humana: o sofista opta por narrar um mito, alegando maior beleza a esse expediente narrativo, além de apelar para o argumento de que o mesmo seria mais condizente com sua idade provecta. (Cf. nota 16, acima). Ora, não parece demasiado supor que Platão reitera aí a impossibilidade de se abordar de outro modo um tema dessa natureza - origens, primeiros princípios - algo que um velho como Protágoras não poderia desconhecer. Donde então a pertinência do mito, dado seu caráter persuasivo. 
psicagogia, ou seja, de condução de almas para o caminho que leva exatamente ao que elas aspiram, a saber, o Belo.

Dada a precariedade da alma e do logos humano que tanto aproximam o filósofo do mero retórico, o caminho rumo ao Belo é longo e extremamente árduo. ${ }^{23}$ Platão parece querer exacerbar essa tensa proximidade quando propõe o discurso de Lísias como aparentemente elogioso à virtude da temperança, uma vez que se mostra consciente dos perigos de Eros e de sua ligação com a loucura, a desrazão. Ademais, leva Sócrates a medir-se com Lísias, vindo a proferir seu primeiro discurso inspirado no daquele, ou seja, ofensivo a Eros e, consequentemente, à Filosofia.

Tudo se passa, portanto, como se estivéssemos fadados a uma precariedade da atividade filosófica que a tornaria quase que inviável, dada a precariedade própria à ferramenta com a qual trabalha, o logos. Contudo, é na reparação proposta pelo discurso de palinodia que se resgatará a possibilidade de exercer a atividade filosófica, para a qual Platão parece justamente se valer daquilo mesmo que se apresentava como um problema. Ou seja, é justamente porque o logos padece de imprecisão que há várias possibilidades de formulá-lo e de usá-lo, cabendo ao filósofo o cuidado de primar pelo sentido com o qual emprega os seus termos, bem como o de adequá-lo à alma daquele a quem se destina. Assim é que, antes de enveredar pela narrativa mítica, Sócrates discorre sobre a existência de diferentes formas positivas de loucura, ${ }^{24}$ dentre as quais se destacaria uma que, além de benfazeja, seria também divina, a ela se identificando o amor envolvido na atividade filosófica (Fedro, 244b-245b). Com isto, mostra que a estreita relação entre amor e loucura - compreendida como doença - admitida por Lísias e reiterada pelo primeiro discurso de Sócrates, não inviabilizaria o amor como um todo, mas apenas aquele do tipo ressaltado em tais discursos, a saber: aquele em que as paixões se tornam tiranas das almas dos que se amam e, subjugando-lhes a razão, assumem a forma mais perniciosa da loucura.

É justamente nesse contexto em que Sócrates afirma que "os deuses desejam a suprema ventura daqueles a quem foi concedida a graça da loucura"; ou seja, no âmbito do já aludido passo 245-c, que Sócrates passa a discorrer sobre a natureza da alma como imortal em sua tripla composição. E é então que constatamos o revezamento entre foreground e background, uma vez que,

23 Não raro Platão lança mão do provérbio segundo o qual as coisas belas são difíceis. Cf. Crátilo, 384b.

24 Valendo-se, inclusive, do uso de três termos diferentes, embora relativamente sinônimos - mania, paranoia e aphron - para referir-se à loucura. Cf. Sallis, J. Being and Logos: Reading the Platonic Dialogues. Bloomington e Indianapolis, Indiana University Press, 1996, p. 170, n.36. 
na segunda parte do diálogo, a partir do passo 276, haverá uma correlação explícita entre alma e discurso. Nesse contexto, Sócrates afirmará que para cada alma deverá haver uma espécie apropriada de discurso, cabendo ao filósofo um rigoroso conhecimento da natureza de ambos - alma e discurso -, a fim de empreender a atividade filosófica propriamente dita, a saber, a dialética.

$\mathrm{Na}$ primeira parte, portanto, essa correlação parece figurar como pano de fundo da descrição acerca da natureza da alma, dado que não seria insensato depreender uma correlação entre a natureza compósita da mesma e a multiplicidade semântica do logos. Nessa perspectiva, parece haver o que acima chamamos de precariedade intrínseca à alma humana e, por conseguinte, uma precariedade correlata àquilo que esta é capaz de produzir - nesse caso, discursos.

Contudo, o que vemos ao mesmo tempo na maestria com que Platão opera todas essas correlações e revezamentos entre plano dramático e plano argumentativo, entre background e foreground, é a possibilidade mesma de reverter o que pode de fato ser pensado como precariedade, caso nos deixemos levar pelo convincente, porém falso, discurso de Lísias. Em outras palavras, é justamente porque o logos é prenhe de polissemias e de diferentes possibilidades de formulação que há sempre a possibilidade de redizermos ou repararmos aquilo que dizemos inadvertidamente. E essa possibilidade se viabiliza quando a alma humana decide, por sua feita, reparar a perda de suas asas e recuperá-las a partir de uma vida dedicada àquela forma de Eros que se identifica à filosofia.

A esse respeito, poderiam ainda dizer os convencidos pelo discurso de Lísias e mesmo pelo primeiro discurso de Sócrates, que o amor não seria uma aventura assaz recomendável, uma vez que a natureza da alma humana padeceria de uma precariedade ainda mais radical que aquela identificada no plano do logos. Isto porque, diferentemente da alma divina, a composição da alma humana contaria com apenas um dos cavalos de boa raça, sendo o outro mestiço e em tudo oposto àquele.

Em primeiro lugar, ao invés de vermos essa característica apenas como precariedade, podemos vê-la também como uma grande conquista na concepção de alma proposta por Platão naquele contexto. Com efeito, podemos depreender do mito da parelha alada que, na medida em que deuses e humanos têm suas almas compostas por elementos não exclusivamente racionais (lembremo-nos de que as almas dos deuses, apesar de contar com ambos os cavalos de boa raça, ainda assim são compostas de cavalos e não só do cocheiro), é dada à condição humana, marcada pela precariedade de sua razão, a possibilidade de compartilhar com os deuses essa imortalidade, ainda 
que de uma forma deficitária, através do amor-ou, do que lhe seria congênere: a filosofia. Com isso, alcança-se de algum modo aquilo que, na tradição poética, era intensamente almejado pelos homens: a imortalidade tão invejada dos deuses..$^{25}$ De resto, sua natureza compósita e ambígua aponta ainda para a possibilidade da filosofia, uma vez que esta não se põe como exercício da sabedoria, mas antes, como amor a esta. Nessa perspectiva, a filosofia poderia ser pensada como a palinodia por excelência, a atividade por meio da qual a precariedade humana pode ser reparada, mediante a possibilidade de se dizer as coisas de outra maneira.

Configurando-se assim como uma aventura amorosa, encarnada, a filosofia conta não somente com expedientes racionais, mas também com o ímpeto dos componentes passionais da alma, sendo esta inclusive por aqueles mesmos avisada acerca da existência do Belo no mundo e, consequentemente, acerca daquilo que a alma filosófica mais anseia: o Belo em si. Como nos ensina o passo 250c do Fedro, não é nem a justiça nem a moderação que se sobressaem entre as ideias puras, mas a Beleza. E é justamente à visão, o órgão mais agudo de nossos sentidos, propiciada pela alma compósita e ambígua, que se nos apresenta a Beleza que nos convidará ao delírio amoroso bem aventurado da filosofia.

\section{Referências}

ARISTÓTELES. Metafisica. Texto Grego com tradução ao lado. Ensaio Introdutório de Giovanni Reale. Tradução portuguesa de Marcelo Perine. São Paulo, Loyola, 2002, Vol II, 695 pgs.

BLONDELL, R. The Play of character in Plato's dialogues. Cambridge, Cambridge University Press, 2004, 452 pgs.

CHANTRAINE, P. Dictionnaire Étymologique de la Langue Grecque. Paris, Éditions Klincksieck, 1980, Vol 1, 608 pgs.

FARNESS, J. Missing Socrates: Problems of Plato's Writing. Pennsylvania, The Pensylvania State University Press, 1991, 206pgs.

FERRARI, G.R.F. Listening to the Cicadas: A study of Plato's Phaedrus. New York, Cambridge University Press, 2002, 293pgs.

HADOT, P. O vôo de Ísis: Ensaio sobre a história da idéia de natureza. Tradução de Mariana Sérvulo. São Paulo, Loyola, 2004, 359 pgs.

HERÁCLITO. Fragmentos Contextualizados. Tradução, apresentação e comentários de Alexandre Costa. Rio de Janeiro, Difel, 2002, 287 pgs. 
ISOCRATES XIII. Against the sophists. Translated by Joshua Tinsdale. in. http:// classicpersuasion.org/pw/isocrates/index.htm

ISÓCRATES X. Helen. Introduction and translation by J. A. Freese. in http:// classicpersuasion.org/pw/isocrates.

KAHN, C. H. Plato and the Socratic dialogue: the Philosophical use of a Literary form. New York, Cambridge University Press, 2004, 431pgs.

MAZZARA, G.'Lysias et Isocrates: ironie et simulation dans le Phèdre'. in. Undestanding the Phaedrus - Proceedings of the Symposium Platonicum, Perugia. Ed. by Livio Rossetti. International Plato studies, v. 1, Sankt Augustin, Academia Verlag 1992, 328 pgs.

MOUZE, L. 'De quoi parle le Fedre?' in. Platon. Phédre. Paris, Librairie Genérale Française, Edition Les Classiques de Philosophie, Livre de Poche, 2007, 315 pgs.

PLATO. Complete Works. Edited by John Cooper. Indianapolis/Cambridge, Hackett Publisihing Company, 1997, 1808 pgs.

. Complete Works (Greek Text). Perseus Digital Library. Edited by Gregory

Cane, Tufts University at: http://www.perseus.tufts.edu/hopper/ Plato.

. Lexicon Plato Index. Testo Greco in CD-ROM. A cura de R Radice.

Milano, Biblia Tecnologie per l'informazione, 2005.

Fedro. Traduzione di Linda Untersteiner Candia. Milano, A Cura di Franco Trabattoni. Edizione Bruno Mondadori, 1996, 205 pgs.

Fedro. Tradução e notas de Pinharanda Gomes. Lisboa, Guimarães Editores, 1989, 144 pgs.

Fedro. Tradução e notas de Edson Bini. São Paulo, Edipro, 2008, 278

pgs.

Phédre. Paris, Librairie Genérale Française, Edition Les Classiques de Philosophie, Livre de Poche, 2007, 315 pgs.

A República. Tradução, introdução e notas de Eleazar Magalhães Teixeira. Fortaleza, Edições UFC, 2009, 371 pgs.

A República. Tradução de Ana Lia Amaral de Almeida Prado. São Paulo, Martins Fontes, 2006, 419 pgs.

A República. Tradução de Maria Helena Rocha Pereira. Lisboa, Fundação Calouste Gulbenkian, 1990, 514 pgs.

Timeu, 29 b-c. Tradução, textos complementares e notas de Edson Bini. São Paulo, Edipro, 2010, 287 pgs.

Protágoras, 320-b c. Tradução e estudo introdutório de Eleazar Magalhães Teixeira. Fortaleza, Edições UFC, 1986, 147 pgs.

Banquete. Tradução, introdução e notas de J. Cavalcante de Souza. Rio de

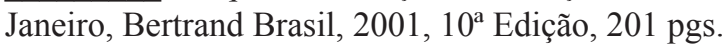

Symposium. Translated by Benjamin Jowett. New York, Prometheus Bokks, 1991, 157pgs.

Laws. Tradução de Benjamin Jowett. New York, Prometheus Books, 2000, 308 pgs. 
REALE, G. História da Filosofia Antiga. São Paulo, Loyola, 1995, Vol. 2, 596 pgs.

SALLIS, J. Being and Logos: Reading the Platonic Dialogues. Bloomington and Indianapolis, Indiana University Press, 1996, 545 pgs.

SAYRE, K. Plato's Literary Garden: How to read a platonic dialogue. Notre Dame Indiana, University of Notre Dame Press, 1995, 292 pgs.

TRABATTONI, F. 'Il Dialogo come 'portavoce' dell'opinione di Platone. Il caso Del Parmenide'. in. BONAZZI, M. \& TRABATTONI, F. (orgs.) Platone e La Tradizione Platonica. Milano, Cisalpino - Instituto Editoriale Universitario, 2003, 335 pgs., pp. 151-178.

VERNANT, J-P. O Universo, os Deuses, os Homens. Tradução de Rosa Freire d'Aguiar. São Paulo, Companhia das Letras, 2000, 209 pgs. 